\title{
La poesía de Salomé Ureña de Henríquez
}

\begin{abstract}
I poesía de Salomé Ureña es poesía de aliento, de estímulo, pero es al mismo tiempo, poesía consagrada al porvenir. Salomé Ureña es poetisa de la generación que floreció poco después de alcanzada la independencia de Santo Domingo en 1844. Esta generación surgió bajo el signo del romanticismo, si bien los clásicos de la España del Siglo de Oro eran la base de su cultura, junto con los poetas españoles, como Meléndez, Quintana y Gallego, que marcan la transición entre el siglo xvIII y el xIX. El tema de la patria en formación, de sus anhelos, sus esperanzas y sus desventuras, es el que primero cautiva la inspiración de los poetas dominicanos.

Para apreciar el valor de la poesía de Salomé Ureña hay que sentirla plenamente vinculada a los afanes de su vida y a las aspiraciones de su tiempo y de su país. Sólo así se revelará lo más íntimo de su personalidad, que es el espíritu de dedicación. Según José Lamarche, "entre nosotros... José Joaquín Pérez y Salomé Ureña representan toda la euritmia social. Son los poetas. El primero entre nosotros fue como un preludio escuchado en los campos de la nacionalidad; Salomé es la nacionalidad misma". 1
\end{abstract}

La República Dominicana seguía perturbada por incesantes contiendas civiles, y Salomé Ureña veía que el progreso y los adelantos de la civilización sólo podían alcanzarse al am-

1 Max Hentiquez Ureña, Panorama histórico de la literatura dominicasa (Río de Janeiro, 1945), p. 142. 
paro de la paz. Exhorta a sus conciudadanos para que depongan la "poderosa espada" y la guarden en memoria de los grandes acontecimientos nacionales, porque "en esta nueva singular cruzada no será de las armas la alta gloria"; y los invita a

salvar triunfantes el altivo muro que levanta en su orgullo la ignorancia.

Nació Salomé Ureña en Santo Domingo el 21 de octubre de 1850, hija del magistrado criollista Nicolás Ureña de Mendoza y de Gregoria Díaz y León. Físicamente era alta, delgada, de tez desteñida, y de pelo harto rizoso. En lo moral era sencilla, excesivamente modesta, inclinada al silencio. Aprendió primeras letras en escuelas públicas del tiempo. Pero adquirió después, con su apasionada afición por los libros, y dirigida por su padre, una esmerada educación que tuvo por fundamento la lectura de los clásicos castellanos.

A los diez y siete años empezó a publicar sus versos - con el nombre de Herminia-, si bien escribía desde los quince. Un año después firmó con su propio nombre sus cantos patrióticos. En 1878 le fue otorgada una medalla costeada por suscripción popular organizada por la sociedad literaria "Amigos del País". En 1880 se casó con don Francisco Henríquez y Carvajal, y publicó su libro de Poesías, prologado por el Presidente Meriño.

En 1880 Fernando Arturo de Meriño había sido electo para regir la República Dominicana. Fue buen augurio para los ideales que siempre había proclamado Salomé Ureña, pero la dura enseñanza de la realidad fue muy otra. Meriño gobernó con habilidad; sin embargo se conspiraba contra su gobierno. Así se encontró al año siguiente frente a un grave dilema: como hombre de ideas liberales sentía aversión por las medidas drásticas; como hombre de gobierno, veía amenazada la estabilidad de su administración. Oído el parecer de sus ministros, firmó un decreto que establecía la ley marcial. Dos meses después el Ministro del Interior, General Ulises Heureux, lo aplicó definitivamente contra los revolucionarios. La poetisa no pudo ocultar su desencanto y previó las sangrientas consecuencias en su poema "Sombras". 


\begin{abstract}
¿No veis? Allá a lo lejos
nube de tempestad siniestra avanza

que oscurece a su paso los reflejos

del espléndido sol de la esperanza.

Mirad cuál fugitivas

las ilusiones van, del alma orgullo;

no como ayer, altivas,

hasta el éter azul tienden el vuelo,

ni a recibirlas, con piadoso arrullo,

sus pórticos de luz entreabre el cielo.2
\end{abstract}

Desencantada ante las turbulencias de la política, se recogió Salomé Ureña en sí misma y se dedicó a la enseñanza. Su entusiasmo por el saber la determinó a fundar en 1881 el Instituto de Señoritas, primer centro de enseñanza superior que tuvo la mujer dominicana. Ese instituto fue el inicio de una verdadera cruzada por la cultura de la mujer, y fue a la vez el complemento de la labor del maestro puertorriqueño Eugenio María Hostos, que reformó la enseñanza en Santo Domingo.

Salomé Ureña puso toda su fe en esta obra. Y, a los seis años, hubo de escribir en la investidura académica de sus primeras discípulas, su lírica "Ofrenda a la patria".

¡Ah! La mujer encierra, a despecho del vicio y su veneno, los veneros inmensos de la tierra, el germen de lo grande y de lo bueno. Más de una vez en el destino humano su imperio se ostentó noble y fecundo: ya es Veturia, y desarma a Coriolano; ya Isabel, y Colón halla otro mundo. Hágase luz en la tiniebla oscura que el femenil espíritu rodea, y en sus alas de amor irá segura del porvenir la salvadora idea. ${ }^{3}$

Con estos versos quebró el silencio que guardaba desde hacía seis años, y así lo declaraba en las estrofas iniciales:

2 En Salomé Ureña de Hentiquez, Poesías completas, Ciudad Trujillo, Impresora Dominicana, 1950), pp. 143-44.

3 En Poesias completas (1950), pp. 146-49. 
¡Hace ya tanto tiempo! ... Silenciosa, si indiferente no, Patria bendita, yo he seguido la lucha fatigosa con que llevas de bien tu ansia infinita.

Ha tiempo que no llena. tus confines la luz de mi esperanza, ni el alma, que contigo se enajena, a señalarte el porvenir se lanza.4

Escribió Salomé Ureña odas en alabanza de la ciencia, de la industria, del trabajo, de todas las actividades dignificantes de la inteligencia humana, pero con la fuerza de una mujer creyente también en las virtudes del espíritu. Vertió en sus versos el vocabulario en que se expresan los poetas civiles, y a la vez supo llevar a ellos una parte de su alma invadida por inquietudes patrióticas e instintos maternales.

La nota cívica de Quintana está presente en Salomé Ureña y el clasicismo sereno de Gallego es también una parte esencial de la poesía de Salomé Ureña. A veces, sin embargo, ella revela una emisión interior que sobrepasa a las normas clásicas de expresión:

$\mathrm{Y}$ arrebatada, luego, ávida el alma recorrió tu historia;

$y$ en el arranque de entusiasmo ciego, espléndida tu gloria

gozosa imaginó la fantasía

que de uno al otro polo se extendía.

Mas jah! nueva existencia

la mente absorta descubrió entre asombros

y descender te vi de la eminencia;

$y$ triste en tus escombros

fui a llorar en la tarde que declina

tu muerta gloria y tu presente ruina...

En la encendida hoguera

del sol que en tus espacios se derrama

$\mathrm{y}$ ardiente reverbera,

de mi entusiasmo se templó la llama,

y a su calor el alma estremecida

bebió la inspiración, la luz, la vida.5

4 Ibid.

5 "A mi patria", en Poesias completas, (1950), pp. 120-23. 
Sus poesías íntimas tienen el mismo sello de delicada emoción, aun en "Quejas" donde se muestra más efusiva:

No basta que cautiva

de fiero padecer entre las redes

agonizante viva?

iAy, que mi angustia comprender no puedes, que por mi mal ignoras

cuán lentas son de mi existir las horas!

Sí, que jamás supiste

cuál se revuelve en su prisión estrecha,

desconsolado y triste,

el pobre corazón, que en lid desecha

con su tormento rudo

morir se siente y permanece mudo. 6

Contiene "En horas de angustia" los sentimientos encontrados que agitan el alma de una madre a quien la muerte le disputa un hijo:

\author{
Pasaron intranquilas \\ horas solemnes de esperanza y duda: \\ latiendo el pecho con violencia ruda, \\ erraban mis pupilas \\ de uno en otro semblante, sin sosiego, \\ con delirio cercano a la demencia; \\ y entre el temor y el ruego \\ juzgaba, de mi duelo en los enojos, \\ escrita tu sentencia \\ hallar de los amigos en los ojos.7
}

Otras cualidades de su poesía son la elevación moral y el sentido de su misión de educadora.

$\mathrm{Y}$ esa es del hombre la misión sublime:

disipar del error la sombra densa,

y a la ignorancia que en tinieblas gime

(1) llevar la luz de la verdad que piensa. ${ }^{8}$

Hasta cuando ella se entrega a la melancolía parece que su

6 Ibid, pp. 159-61.

7 En Poesia completas (1950), pp. 172-74.

8 "En defensa de la sociedad", Poesías completas, pp. 215-19. 
propia angustia le sirve sólo de pretexto para darnos una lección de energía moral:

No pido más: bien pueden los dolores destrozar sin piedad las bellas flores

de la ilusión que amé;

que jamás, bajo el peso que me oprime, mientras un rayo de virtud me anime,

la frente inclinaré. ${ }^{\circ}$

o cuando la realidad social de entonces, con todas sus caídas, la desalienta, la esperanza acude a reanimar su espíritu para exhortar de esta suerte a la patria:

Inclínate $\mathrm{y}$ escucha:

del seno de esa tumba esclarecida, se eleva conmovida

voz que la unión y la concordia clama, y los males deplora de tu lucha y al goce de la paz tus hijos llama.

Restaña tus heridas, de la civil discordia fruto aciago; levanta tus miradas abatidas, mira del porvenir el fiero amago que amenaza tal vez con golpes ciertos convertir tus ciudades en desiertos y tus campiñas en sangriento lago. ${ }^{10}$

Salomé Ureña escribe siguiendo las reglas tradicionales: Prefiere la silva y otras combinaciones estróficas igualmente fáciles y naturales, y en su aversión al soneto y a otras formas de versificación artificiosa.

Memorias venerandas de otros días, soberbios monumentos, del pasado esplendor reliquias frías, donde el arte vertió sus fantasías, donde el alma expresó sus pensamientos. ${ }^{11}$

Poca o ninguna afición mostró a los artificios de la versificación y del lenguaje. Usó con timidez aun las licencias más

9 "Melancolia", Ibid, pp. 153-55.

10 "En la muerte de Espaillat", op cit., pp. 108-11.

11 "Ruinas", op. cit., pp. 94-96. 
comunes. Lo que caracteriza su poesía en este aspecto es la tendencia a no dar lugar en su verso más que a aquellos procedimientos retóricos que se han incorporado a la lengua y pasan por normas consagradas. Hay en sus poesías muchos versos, sobre todo de endecasílabos, que carecen no sólo de licencias artificiales sino también de elisiones:

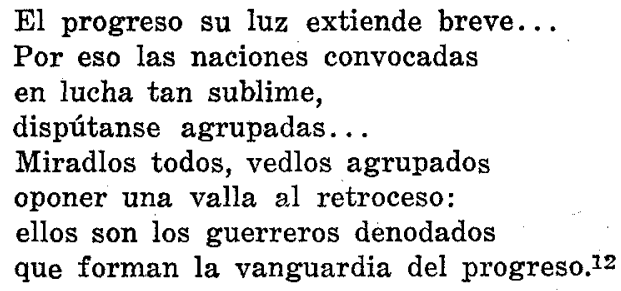

Según Joaquín Belaguer, la obra poética de Salomé Ureña “es limpia, es pulcra, es nítida, sin que ningún detalle muestre que ha sido prolijamente cincelada. Su perfección relativa no nace de pulimento exagerado sino de su apego a las formas clásicas y de su amor a la sobriedad sentenciosa". ${ }^{13}$

En la poesía hispanoamericana del siglo XIX antes del modernismo, Salomé Ureña nos ofrece una nota de elegante y casta belleza. Hay a veces acentos de íntimo lirismo en su obra, así como un sentimiento de la naturaleza. Pero no es suyo el gran tema del amor en todas las variaciones de Delmira Agustini, ni de Alfonsina Storni; no es suya la obra de pura creación de Gabriela Mistral. Es amor a la tierra en que nació, es el celo e interés por el decoro del hombre, por su perfección, por su libertad, que son los motivos más importantes que impresionan la sensibilidad de Salomé Ureña. Ella vive los dolores y las esperanzas de la patria; exalta sus glorias y sus triunfos. Salomé Ureña quiere impulsar a la nación por la senda de la paz, del decoro y del progreso.

\author{
RUTH S. LAMB, \\ Scripps College, \\ Claremont, California
}


